\title{
Depression, Anxiety and Stress among Undergraduate Students: A Cross Sectional Study
}

\author{
Choon Khim Teh*, Choon Wei Ngo, Rashidatul Aniyah binti Zulkifli, Rammiya Vellasamy, \\ Kelvin Suresh \\ Melaka Manipal Medical College, Melaka, Malaysia \\ Email: *choonkhim91@hotmail.com
}

Received 26 October 2015; accepted 21 November 2015; published 24 November 2015

Copyright (C) 2015 by authors and Scientific Research Publishing Inc.

This work is licensed under the Creative Commons Attribution International License (CC BY). http://creativecommons.org/licenses/by/4.0/

(c) (i) Open Access

\section{Abstract}

Background: The prevalence of moderate to extremely severe level of depression, anxiety and stress among undergraduate students in Malaysia was ranging from $13.9 \%$ to $29.3 \%, 51.5 \%$ to $\mathbf{5 5 . 0 \%}$ and $\mathbf{1 2 . 9 \%}$ to $21.6 \%$ respectively. Medical students have been shown to be more inclined to emotional disorders, especially stress and depression, as compared to their non-medical peers. Therefore, the objective of this cross-sectional study was to determine the prevalence of depression, anxiety and stress among undergraduate students in Melaka Manipal Medical College. Methods: Self-administered questionnaires consisted of 3 sections: demographic data, socioeconomic data and DASS 21 questions. Data processing was performed using Microsoft Excel 2010. The psychological status was categorized according to the presence or absence of depression, anxiety and stress. The data were analyzed using Epi Info ${ }^{\mathrm{TM}}$ 7.1.4 and SPSS. Student's t-test, Fisher Exact and Chi-square test were used to analyze the associations. P-value of $<0.05$ was considered as statistically significant. Multiple logistic regression was used to calculate the adjusted Odd Ratio. Results: A total of 397 undergraduates participated in this study. The prevalence of the depression, anxiety and stress, ranging from moderate to extremely severe, was $30.7 \%, 55.5 \%$, and $16.6 \%$ respectively. Multiple logistic regression shows significant associations between relationship status, social life and total family income per month with depression. Only ethnicity has been shown to be significantly associated with anxiety. There are significant associations between ethnicity and total family income per month with stress. No other factors have been found to be significantly associated. Conclusion: Depression, anxiety and stress have a high detrimental effect to individual and society, which can lead to negative outcomes including medical dropouts, increased suicidal tendency, relationship and marital problems, impaired ability to work effectively, burnout and also existing problems of health care provision. With that, there is a need for greater attention to the psychological wellbeing of undergraduate students to improve their quality of life.

\footnotetext{
${ }^{*}$ Corresponding author.
}

How to cite this paper: Teh, C.K., Ngo, C.W., Zulkifli, R.A., Vellasamy, R. and Suresh, K. (2015) Depression, Anxiety and Stress among Undergraduate Students: A Cross Sectional Study. Open Journal of Epidemiology, 5, 260-268. 


\section{Keywords}

\section{Prevalence, Depression, Anxiety, Stress, Undergraduates, Melaka Manipal Medical College}

\section{Introduction}

According to WHO definition, "Health is a state of complete physical, mental and social well-being and not merely the absence of disease or infirmity" [1]. Many people perceive health as being physically well and free of any diseases, and thus they have neglected the importance of mental health. Therefore, mental health is an irreplaceable aspect of health. Poor mental health will lead to many life threatening diseases such as cardiovascular disease deaths, deaths from external causes or even cancer deaths, which was only associated with psychological distress at higher levels [2].

Depression, anxiety and stress levels in the community are considered as important indicators for mental health. Failure to detect and address to these emotional disorders will unfortunately lead to increased psychological morbidity with undesirable impacts all through their professions and lives [3].

In public medical universities, the prevalence of depression and anxiety ranged from $10.4 \%$ to $43.8 \%$ and $43.7 \%$ to $69 \%$ respectively. However, the prevalence of depression and anxiety among private medical students has been estimated to be $19 \%$ to $60 \%$ and $29.4 \%$ to $60 \%$ respectively [4]. In Hong Kong, a web-based survey of stress among the first-year tertiary education students found that $27 \%$ of the respondents were having stress with moderate severity or above [5]. While in India, a study was conducted to focus on the prevalence of current depression, anxiety, and stress-related symptoms among young adults, ranging from mild to extremely severe, which was $18.5 \%, 24.4 \%$, and $20 \%$ respectively. Clinical depression was present in $12.1 \%$ and generalized anxiety disorder in $19.0 \%$. Co-morbid anxiety and depression were high, with about $87 \%$ of those having depression also suffering from anxiety disorder [6].

A research conducted in Malaysia showed that the prevalence of moderate to extremely severe level of depression, anxiety and stress among undergraduate students was ranging from $13.9 \%$ to $29.3 \%, 51.5 \%$ to $55.0 \%$ and $12.9 \%$ to $21.6 \%$ respectively [7] [8].

With respect to the source of stressors, the top ten stressors chosen by the students were mainly academic and personal factors [9]. As indicated by Porter, there were up to $60 \%$ of university dropouts recorded; the majority of these students leave within the first two years. Steinberg and Darling specified that $50 \%$ of university students who consulted mental health service complained of challenges in study, anxiety, tension, and depression which contributed to poor grades in courses [10].

In Malaysia, tertiary learning institutions offering medical degrees have expanded in numbers in the previous couple of years to meet the nation's demand for more graduate doctors and medical personnel. All things considered, the environment of medical education and practice has long been viewed as a distressing factor [11]. Medical students have been shown to be more inclined to emotional disorders, especially stress and depression, as compared to their non-medical peers.

Therefore, we conducted the cross-sectional study to determine the prevalence of depression, anxiety and stress among undergraduate students in Melaka Manipal Medical College.

\section{Methodology}

This cross-sectional study was done among undergraduate students, from September to October 2014 in Melaka Manipal Medical College (Melaka Campus), Malaysia.

We calculated the sample size using prevalence of 55.0\% [7]. With the 95\% CI and precision of 5\%, we require a total sample size of 384 students. After accommodate the non-response rate of $10 \%$, we distributed 430 sets of the questionnaires. A total of 397 undergraduate students participated in this study. Written informed consent was taken from every participant. The students who were absent for class on the day of data collection were excluded from this study.

This study helps to arbitrate the differences in psychological distress with respect to the demographic variables among MMMC students. There are several stress reducing factors (stress busters) and are divided into 6 groups: friends, gym workouts, physical factors, co-curricular activities, teacher's patronage and personal hob- 
bies.

Self-administered questionnaires consisted of 3 sections: Demographic data, socioeconomic data and DASS 21 questions. Demographic data consists of 8 questions based on personal details: age, gender, ethnicity, study course, residence, relationship status, academic performance and social life status. The socioeconomic data include parental marital status and total family income per month.

The Depression Anxiety Stress Scale (DASS 21, Psychology Foundation of Australia) was used to screen mental health problems among the population [12]. The DASS 21 is a 21 item self report questionnaire devised to measure and assesses the severity of a range of symptoms common to depression, anxiety and stress. However, it is not a categorical measure of clinical diagnoses of the said conditions [13].

In completing the DASS 21 questionnaire, the individual is required to indicate the presence of a symptom over the previous week. DASS 21 consists of 21 questions in total which was designated for participants to specify their emotional level for each statement. In total, there are 7 items for each depression, anxiety and stress assessment [14]. Each item is scored from 0 (did not apply to me at all over the last week) to 3 (applied to me very much or most of the time over the past one week) [15]. Because the DASS 21 is a short form version of the DASS (the Long Form has 42 items), the final score of each item groups (depression, anxiety and stress) must be multiplied by two $(\times 2)$ [12]. The minimum score is zero and the maximum score is 42 . The final score of DASS can be categorized as in Table 1.

Studies have shown that the DASS 21 score have validity in the measurement of the degree of depression, anxiety and stress in the person. It also has high reliability in terms of usage in a clinical and non-clinical setting [16] [17].

Data processing was performed using Microsoft Excel 2010. The psychological status was categorized according to the presence or absence of depression, anxiety and stress. Data was analyzed using Epi Info ${ }^{\mathrm{TM}}$ 7.1.4 and SPSS. Descriptive statistics such as frequency (\%), mean and standard deviation (SD) were also described. The Student's t-test, Fisher's exact test and Chi-square test were used for bivariate analysis. The variables which had P-value $<0.1$ were included in multiple logistic regression analysis. P-value of $<0.05$ was considered as statistically significant.

The study was carried out by giving a brief introduction on the purpose of the research and the procedures involved prior to distribution of questionnaire. Participants were then informed about their rights to not participate in the study and written consent was taken before they answered the questionnaire. Confidentiality of participants' information given was preserved. This study was conducted under the permission of the research committee of Melaka Manipal Medical College (MMMC).

\section{Results}

Table 2 shows the descriptive statistics of demographic and socioeconomic factors among respondents. The average age of the respondents is 21.9 years old with a range of 18 to 24 years old. $63.2 \%$ of the respondents are female and the remaining $36.8 \%$ are male respondents. Chinese contribute to the largest portion of the ethnic group (34.5\%), followed by Malay (33.3\%), Indian (28.5\%) and lastly others (3.8\%). Many of the respondents are single (73.8\%), followed by those who are in the relationship (26.2\%). For the academic performance, $2.8 \%$ and $28.0 \%$ of the respondents are very satisfied and satisfied with their results respectively. However, most of the respondents (69.3\%) have least satisfaction with their performance. Besides, 7.1\% respondents are very satisfied with their social life, $49.1 \%$ are just satisfied, while $43.8 \%$ has least satisfaction. $94.5 \%$ of the respondents'

Table 1. Severity of depression, anxiety and stress.

\begin{tabular}{cccc}
\hline Rating & Depression & Anxiety & Stress \\
\hline Normal & $0-9$ & $0-7$ & $0-14$ \\
Mild & $10-13$ & $8-9$ & $15-18$ \\
Moderate & $14-20$ & $10-14$ & $19-25$ \\
Severe & $21-27$ & $15-19$ & $26-33$ \\
Extremely Severely & $28+$ & $20+$ & $37+$ \\
\hline
\end{tabular}


parents are happily married, 3.5\% respondents are either orphan or from single parent family.

Table 3 shows the prevalence of depression, anxiety and stress among undergraduates. Depression, anxiety and stress are divided into 5 categories, which are normal, mild, moderate, severe and extremely severe. In depression, $54.2 \%$ of the respondents are normal while $15.1 \%, 20.9 \%, 6.3 \%$ and $3.5 \%$ of the respondents have mild, moderate, severe and extremely severe depression respectively. Mean \pm Standard Deviation for depression score is $9.8 \pm 7.9$. For the anxiety status, $36.0 \%$ of the respondents are free from it while the rest, ranging from

Table 2. Descriptive statistics of socio-demographic factors among medical undergraduates $(\mathrm{n}=397)$.

\begin{tabular}{lc}
\hline Variables & Numbers (\%) \\
\hline Age (Mean \pm Std Deviation) & $21.9 \pm 2.2$ \\
Gender & $251(63.2)$ \\
$\quad$ Female & $146(36.8)$ \\
Male & \\
Ethnicity & $137(34.5)$ \\
$\quad$ Chinese & $132(33.3)$ \\
Malay & $113(28.5)$ \\
Indian & $15(3.8)$ \\
Others & \\
Relationship Status & $104(26.2)$ \\
In a relationship & $293(73.8)$ \\
Single & \\
Academic Performance & $111(28.0)$ \\
Satisfied & $275(69.3)$ \\
Least satisfied & $11(2.8)$ \\
Very satisfied & \\
Social Life & $195(49.1)$ \\
Satisfied & $174(43.8)$ \\
Least satisfied & $28(7.1)$ \\
Very satisfied & \\
Parental Status & $375(94.5)$ \\
Married & $22(3.5)$ \\
Orphan/Single parent &
\end{tabular}

Table 3. Prevalence of depression, anxiety and stress among undergraduates $(n=397)$.

\begin{tabular}{lc}
\hline Variables & Number (\%) \\
\hline Depression & $215(54.2)$ \\
Normal & $60(15.1)$ \\
Mild & $83(20.9)$ \\
Moderate & $25(6.3)$ \\
Severe & $14(3.5)$ \\
Extremely severe & $9.8 \pm 7.9$ \\
Mean \pm Std Deviation & \\
Anxiety & $143(36.0)$ \\
Normal & $34(8.6)$ \\
Mild & $121(30.5)$ \\
Moderate & $4.0(10.1)$ \\
Severe & $59(14.9)$ \\
Extremely severe & $11.0 \pm 7.7$ \\
Mean \pm Std Deviation & \\
Stress & $270(68.0)$ \\
Normal & $61(15.4)$ \\
Mild & $43(10.8)$ \\
Moderate & $20(5.0)$ \\
Severe & $3(0.8)$ \\
Extremely severe & $12.7 \pm 12.8$ \\
Mean \pm Std Deviation &
\end{tabular}


$8.6 \%$ to $30.5 \%$ have mild to extremely severe anxiety. Mean \pm Standard Deviation for anxiety score is $11.0 \pm$ 7.7. Moreover, $68.0 \%$ of the respondents do not have any stress. Those who are with mild level of stress consist of $15.4 \%$, followed by moderate level of stress (10.8\%), severe level of stress $(5.0 \%)$ and lastly extremely severe level of stress $(0.8 \%)$. Mean \pm Standard Deviation for stress score is $12.7 \pm 12.8$.

Table 4 shows the association between socio-demographic factors and depression, anxiety and stress among the respondents. There are no significant association between socio-demographic factors and depression. However, the students who are least satisfied to social life (Unadjusted OR 2.0; 95\% CI 1.3 - 3.1) and the students who have total family income of $<$ RM1000 per month (Unadjusted OR 3.4; 95\% CI 1.0 - 11.3) are significantly more likely to have depression. Regarding anxiety, there are no significant association between socio-demographic factors and anxiety, but Malay students are significantly more likely to have anxiety (Unadjusted OR 2.1; 95\% CI 1.2 - 3.4). Regarding stress, there are no significant association between socio-demographic factors and stress. However, the students who are least satisfied to social life (Unadjusted OR 1.6; 95\% CI 1.0 - 2.4) and the students who have total family income of <RM1000 per month (Unadjusted OR 6.2; 95\% CI 1.9 - 20.7) are significantly more likely to have stress.

The variables which had P-value $<0.1$ in bivariate analysis were included in multiple logistic regression analysis. Table 5 shows the multiple logistic regression analysis of socio-demographic factors and depression,

Table 4. Bivariate analysis of socio-demographic factors and depression, anxiety and stress.

\begin{tabular}{|c|c|c|c|}
\hline Variables & $\begin{array}{c}\text { Depression }(\mathrm{n}=182) \\
\text { Unadjusted OR }(95 \% \mathrm{CI})\end{array}$ & $\begin{array}{c}\text { Anxiety }(\mathrm{n}=256) \\
\text { Unadjusted OR }(95 \% \mathrm{CI})\end{array}$ & $\begin{array}{c}\text { Stress }(\mathrm{n}=127) \\
\text { Unadjusted OR }(95 \% \mathrm{CI})\end{array}$ \\
\hline $\operatorname{Age}^{t}($ Mean \pm SD $)$ & $22.1 \pm 2.0$ & $22.0 \pm 2.3$ & $22.1 \pm 2.0$ \\
\hline $\begin{array}{l}\text { Sex }^{\mathrm{C}} \\
\quad \text { Female } \\
\quad \text { Male }\end{array}$ & $\begin{array}{l}1 \text { (Reference) } \\
1.0(0.7-1.6)\end{array}$ & $\begin{array}{l}1 \text { (Reference) } \\
0.9(0.6-1.4)\end{array}$ & $\begin{array}{l}1 \text { (Reference) } \\
0.8(0.5-1.2)\end{array}$ \\
\hline $\begin{array}{l}\text { Ethnicity } \\
\text { Chinese } \\
\text { Malay } \\
\text { Indian } \\
\text { Others }\end{array}$ & $\begin{array}{l}1 \text { (Reference) } \\
1.5(0.9-2.4) \\
1.4(0.8-2.3) \\
1.3(0.4-3.8)\end{array}$ & $\begin{array}{c}1 \text { (Reference) } \\
2.1(1.2-3.4)^{* *} \\
1.6(0.9-2.7) \\
0.9(0.3-2.7)\end{array}$ & $\begin{array}{l}1 \text { (Reference) } \\
1.8(1.1-3.1) \\
1.4(0.8-2.4) \\
1.5(0.5-4.6)^{\mathrm{F}}\end{array}$ \\
\hline $\begin{array}{l}\text { Study Course }^{\mathrm{C}} \\
\quad \text { FIS } \\
\text { MBBS }\end{array}$ & $\begin{array}{l}1 \text { (Reference) } \\
1.6(1.0-2.6)\end{array}$ & $\begin{array}{l}1 \text { (Reference) } \\
0.9(0.6-1.5)\end{array}$ & $\begin{array}{l}1 \text { (Reference) } \\
1.3(0.8-2.3)\end{array}$ \\
\hline $\begin{array}{l}\text { Residence }^{\mathrm{C}} \\
\text { Non-hostelile } \\
\text { Hostelite }\end{array}$ & $\begin{array}{l}1 \text { (Reference) } \\
1.0(0.6-1.4)\end{array}$ & $\begin{array}{l}1 \text { (Reference) } \\
1.0(0.7-1.5)\end{array}$ & $\begin{array}{l}1 \text { (Reference) } \\
0.8(0.5-1.2)\end{array}$ \\
\hline $\begin{array}{l}\text { Relationship Status }^{\mathrm{C}} \\
\text { In a relationship } \\
\text { Single }\end{array}$ & $\begin{array}{l}1 \text { (Reference) } \\
1.4(0.9-2.1)\end{array}$ & $\begin{array}{l}1 \text { (Reference) } \\
1.5(1.0-2.4)\end{array}$ & $\begin{array}{l}1 \text { (Reference) } \\
0.9(0.6-1.5)\end{array}$ \\
\hline $\begin{array}{l}\text { Academic Performance } \\
\text { Satisfied } \\
\text { Least satisfied } \\
\text { Very satisfied }^{\mathrm{C}}\end{array}$ & $\begin{array}{l}1 \text { (Reference) } \\
1.5(1.0-2.4) \\
1.3(0.4-4.6)\end{array}$ & $\begin{array}{l}1 \text { (Reference) } \\
1.4(0.9-2.2) \\
0.8(0.2-3.0)\end{array}$ & $\begin{array}{l}1 \text { (Reference) } \\
1.2(0.8-2.0) \\
1.4(0.4-5.1)\end{array}$ \\
\hline $\begin{array}{l}\text { Social Life }^{\mathrm{C}} \\
\text { Satisfied } \\
\text { Least satisfied } \\
\text { Very satisfied }\end{array}$ & $\begin{array}{l}1 \text { (Reference) } \\
2.0(1.3-3.1)^{* * *} \\
0.6(0.3-1.5)\end{array}$ & $\begin{array}{l}1 \text { (Reference) } \\
1.5(0.9-2.2) \\
0.6(0.3-1.4)\end{array}$ & $\begin{array}{l}1 \text { (Reference) } \\
1.6(1.0-2.4)^{*} \\
0.7(0.3-1.8)\end{array}$ \\
\hline $\begin{array}{l}\text { Parental Status }^{\mathrm{C}} \\
\text { Married } \\
\text { Orphan/Single parent }\end{array}$ & $\begin{array}{l}1 \text { (Reference) } \\
0.8(0.3-1.9)\end{array}$ & $\begin{array}{l}1 \text { (Reference) } \\
0.5(0.2-1.3)\end{array}$ & $\begin{array}{l}1 \text { (Reference) } \\
0.6(0.2-1.7)\end{array}$ \\
\hline $\begin{array}{l}\text { Total Family Income per } \\
\text { > RM6000 } \\
\text { <RM1000 } \\
\text { RM1000 - RM3000 } \\
\text { RM3001 - RM6000 }\end{array}$ & $\begin{array}{c}1 \text { (Reference) } \\
3.4(1.0-11.3)^{*} \\
1.1(0.6-1.9) \\
1.3(0.8-2.1)\end{array}$ & $\begin{array}{c}1 \text { (Reference) } \\
2.0(0.5-7.5)^{\mathrm{F}} \\
1.1(0.6-1.9) \\
0.8(0.5-1.3)\end{array}$ & $\begin{array}{c}1 \text { (Reference) } \\
6.2(1.9-20.7)^{\mathrm{F} * *} \\
1.1(0.6-2.0) \\
1.2(0.8-2.0)\end{array}$ \\
\hline
\end{tabular}

${ }^{\text {t}}$ Student's t-test; ${ }^{\mathrm{C}}$ Chi-square; ${ }^{\mathrm{F}}$ Fisher exact; ${ }^{*} \mathrm{P}$ value $<0.05 ;{ }^{* *} \mathrm{P}$ value $<0.01 ;{ }^{* * *} \mathrm{P}$ value $<0.001$. 
Table 5. Multiple logistic regression analysis of socio-demographic factors and depression, anxiety and stress.

\begin{tabular}{|c|c|c|c|}
\hline Variables & $\begin{array}{c}\text { Depression } \\
\text { Adjusted OR }(95 \% \mathrm{CI})\end{array}$ & $\begin{array}{c}\text { Anxiety } \\
\text { Adjusted OR (95\% CI) }\end{array}$ & $\begin{array}{c}\text { Stress } \\
\text { Adjusted OR }(95 \% \mathrm{CI})\end{array}$ \\
\hline \multicolumn{4}{|l|}{ Ethnicity } \\
\hline Chinese & 1 (Reference) & 1 (Reference) & 1 (Reference) \\
\hline Malay & $1.5(0.9-2.4)$ & $2.1(1.2-3.6)^{* * *}$ & $2.0(1.2-3.5)^{*}$ \\
\hline Indian & $1.6(1.0-2.8)$ & $1.5(0.9-2.6)$ & $1.5(0.8-2.6)$ \\
\hline Others & $2.0(0.6-6.0)$ & $1.0(0.3-2.9)$ & $1.8(0.5-5.8)$ \\
\hline \multicolumn{4}{|l|}{ Study Course } \\
\hline FIS & 1 (Reference) & 1 (Reference) & 1 (Reference) \\
\hline MBBS & $1.7(1.0-3.2)$ & $0.7(0.4-1.3)$ & $1.1(0.6-2.1)$ \\
\hline \multicolumn{4}{|l|}{ Relationship Status } \\
\hline In a relationship & 1 (Reference) & 1 (Reference) & 1 (Reference) \\
\hline Single & $1.6(1.0-2.7)^{*}$ & $1.5(0.9-2.4)$ & $1.0(0.6-1.6)$ \\
\hline \multicolumn{4}{|l|}{ Academic Performance } \\
\hline Satisfied & 1 (Reference) & 1 (Reference) & 1 (Reference) \\
\hline Least satisfied & $0.9(0.5-1.6)$ & $1.3(0.7-2.23)$ & $0.9(0.5-1.6)$ \\
\hline Very satisfied & $1.8(0.4-7.0)$ & $1.3(0.4-4.9)$ & $2.0(0.5-7.9)$ \\
\hline \multicolumn{4}{|l|}{ Social life } \\
\hline Satisfied & 1 (Reference) & 1 (Reference) & 1 (Reference) \\
\hline Least satisfied & $2.1(1.3-3.5)^{* * *}$ & $1.5(0.9-2.4)$ & $1.6(1.0-2.7)$ \\
\hline Very satisfied & $0.5(0.2-1.3)$ & $0.6(0.2-1.3)$ & $0.5(0.2-1.4)$ \\
\hline \multicolumn{4}{|c|}{ Total Family Income per Month } \\
\hline$>$ RM6000 & 1 (Reference) & 1 (Reference) & 1 (Reference) \\
\hline$<$ RM1000 & $3.8(1.0-13.8)^{*}$ & $2.8(0.7-11.2)$ & $7.7(2.1-28.2)^{* *}$ \\
\hline RM1000 - RM3000 & $1.0(0.5-1.8)$ & $1.0(0.5-1.8)$ & $1.0(0.6-2.0)$ \\
\hline RM3001 - RM6000 & $1.3(0.8-2.0)$ & $0.8(0.5-1.2)$ & $1.2(0.7-2.0)$ \\
\hline
\end{tabular}

${ }^{*}$ P value $<0.05 ;{ }^{* *} \mathrm{P}$ value $<0.01 ;{ }^{* * * *} \mathrm{P}$ value $<0.001$.

anxiety and stress. Regarding depression, the students who are single (Adjusted OR 1.6; 95\% CI 1.0 - 2.7), least satisfied to social life (Adjusted OR 2.1; 95\% CI 1.3 - 3.5) and having total family income <RM1000 per month (Adjusted OR 3.8; 95\% CI 1.0 - 13.8) are significantly more likely to have depression. However, there are no significant association between other socio-demographic factors and depression. Similarly, there are no significant association between socio-demographic factors and anxiety, but Malay students are significantly more likely to have anxiety (Adjusted OR 2.1; 95\% CI 1.2 - 3.6). Regarding stress, Malay students are significantly more likely to have stress (Adjusted OR 2.0; 95\% CI 1.2 - 3.5) and having total family income <RM1000 per month (Adjusted OR 7.7; 95\% CI 2.1 - 28.2). There are no significant association between other socio-demographic factors and stress.

\section{Discussion}

The objective of the study is to determine the prevalence of depression, anxiety and stress among undergraduate students in Malaysia. In the present study, prevalence for moderate to extremely severe depression, anxiety and stress are $30.7 \%, 55.5 \%$, and $16.6 \%$ respectively. This is lower than one study done among Malaysian university students whereby the percentages are $37.2 \%, 63.0 \%$, and $23.7 \%$ for depression, anxiety and stress [18]. A higher prevalence of depression, anxiety and stress could be attributed to the fact that enormous syllabus has to be covered in a limited time period, sudden change in their style of studying, thought of appearing or failing in exams, inadequate time allocated to clinical posting have become the main factors. Furthermore, social stress such as relationship with peer groups, hostel friends, displacement from home and financial problem have also potentially psychologically influence undergraduate students greatly. This study is conducted done to determine the differences in elevated psychological distress with respect to the demographic variables among MMMC students.

To the best of our knowledge, no study has found association between relationship status and depression. We hypothesised that single individuals are more likely to have depression due to the fact that they may lack a partner to express their daily stressors, thereby lacking social support and social buffer. Social life has invariably 
been associated with depression. It has been shown that individuals, who are satisfied with their social life and thus, a good social support, has a good social support, has shown more resilience to stressors in life, hence acting as a life buffer. This minimizes the risk of developing depression [19] [20]. In the present study, students with total family income per month of less than RM1000 are more likely to have depression. This is consistent with studies which also shows that lower socioeconomic status are strongly associated with major depressive disorder and depressive symptomatology [21]. Lefkowitz et al. also found that lower family income are associated with higher prevalence of childhood depression [22]. Students with lower total family income per month may encounter problem with everyday’s expenses and thus contributing to the precipitating factors for depression.

Malay ethnicity has been shown to be significantly more likely in developing anxiety and stress. According to Khadijah Shamsuddin et al., they found that Malay ethnicity has a higher stress score on DASS as compared to their other ethnic counterparts [18]. This could be due to cultural differences. We postulate that Malays are more susceptible to stress due to cultural factors. However, this is in contradiction to an earlier study on medical students in a Malaysian university, which reported no difference in emotional distress among Malays, Chinese, Indians and students from other ethnicity [23]. Total family income per month less than RM1000 is significantly associated with risk of having stress. We postulate that this to be due to addition of stressors to the lives of students, particularly to sustain everyday's living expenditures as well as the already-costly medical education. One study has also shown that socioeconomic status, especially parents' education and income, indirectly relates to children's academic achievement through parents' belief and behaviours [24].

Our study did not find any significant association between age, sex, study course, residence, academic performance and parental status with depression, anxiety and stress.

To pinpoint some limitations of our study, we had chosen an analytical cross-sectional study which has the disadvantage of being unable to establish the incidence rate of the mental health status of MMMC students. We can only determine the prevalence of the psychological distress among the students. Besides, lack of baseline information concerning mental status of medical students has become a limitation of our study. Since our study was done only among the medical students from a single private medical college, who are more likely to have high levels of stress, selection bias might be present. Associations among all these might not be representative of the general population because this study is only focus on undergraduates.

Other than this, the students may not remember the events happened last week which might disturb their emotion. Also, the life events happen might not cause an immediate change in an individual's mental status. Hence, to understand the temporal relationship and the mechanism of how these risk factors may affect one's mental state, it will require not only longitudinal data throughout the lifetime but also regular assessment of individual's mental health with the consistent measurement of level of exposure to each risk factor intermittently.

Emotional disturbances in the form of depression, anxiety and stress exist are existing in high rate among undergraduate science students that require early intervention [25]. We recommend that to achieve a healthy life as per define by WHO [1], students are encouraged to spend adequate time on their social and personal lives and emphasize the importance of health promoting coping strategies which might be helpful in overcoming stress throughout their medical condition. Academy management-wise, a student counseling centre with adequate facilities and qualified staff should be established in the campus to provide a medium for students to seek appropriate help for mental health problems. Also, preventive programming efforts should be introduced and begin early in medical education and address a wide variety of concerns from academic to interpersonal relationship and financial worries. Early signs of depressive symptoms among students should be addressed. Intervention will help students to cope with stress to make a smooth transition through medical college and also to adjust to different learning environments during different phases of medical education.

\section{Conclusion}

In conclusion, depression, anxiety and stress have a high detrimental effect to individual and society, which can lead to negative outcomes including medical dropouts, increased suicidal tendency, relationship and marital problems, impaired ability to work effectively, burnout and also existing problems of health care provision. With that, there is a need for greater attention to the psychological wellbeing of undergraduate students to improve their quality of life. 


\section{Acknowledgements}

We would like to thank undergraduate students for their kind volunteering for the research and also to our college, Melaka Manipal Medical College, for the approval for research. Our gratitude to Associate Professor Dr. Htoo Htoo Kyaw Soe, Department of Community Medicine, Melaka Manipal Medical College for her valuable advice on the statistical analysis and interpretation of the data. Also, we would like to express gratitude to Professor Dr. Adinegara bin Lutfi Abas, Head of Department, Department of Community Medicine, Melaka Manipal Medical College, for his guidance and approval for the conduct of the study, without which would have been proved difficult for us. Lastly, we would like to thank Tay Geng Yi, Mohd Adi Zafri bin Jasmani and Muhammad Syahid bin Jafri for helping in data collection.

\section{References}

[1] World Health Organization (2013) WHO Definition of Health. WHO, Geneva. http://www.who.int/about/definition/en/print.html

[2] Russ, T.C., Stamatakis, E., Hamer, M., Starr, J.M., Kivimaki, M. and Batty, G.D. (2013) Association between Psychological Distress and Mortality: Individual Participant Pooled Analysis of 10 Prospective Cohort Studies. British Medical Journal, 345, e4933. http://dx.doi.org/10.1136/bmj.e4933

[3] Al-Naggar, R.A. and Al-Naggar, D.H. (1987) Prevalence and Associated Factors of Emotional Disorders among Malaysian University Students. International Journal of Collaborative Research on Internal Medicine \& Public Health, 4. http://internalmedicine.imedpub.com/prevalence-and-associated-factors-of-emotional-disorderamong-malaysian-univer sity-students.pdf

[4] Saravanan, C. and Wilks, R. (2014) Medical Students’ Experience of and Reaction to Stress: The Role of Depression and Anxiety. The Scientific World Journal, 2014, Article ID 737382. http://dx.doi.org/10.1155/2014/737382

[5] Wong, J.G.W.S., Cheung, E.P.T., Chan, K.K.C., Kamela, K.M. and Tang, S.W. (2006) Web-Based Survey of Depression, Anxiety and Stress in First-Year Tertiary Education Students in Hong Kong. Australian and New Zealand Journal of Psychiatry, 40, 777-782. http://dx.doi.org/10.1080/j.1440-1614.2006.01883.x

[6] Saddichha, S. and Christoday, K.R.J. (2010) Prevalence of Depression, Anxiety, and Stress among Young Male Adults in India: A Dimensional and Categorical Diagnoses-Based Study. Journal of Nervous \& Mental Disease, 198, 901-904. http://dx.doi.org/10.1097/NMD.0b013e3181fe75dc

[7] Gan, W.Y., Mohd Nasir, M.T., Shariff, Z.M. and Hazizi, A.S. (2011) Disordered Eating Behaviours, Depression, Anxiety and Stress among Malaysian University Students. College Student Journal, 45, 296.

http://connection.ebscohost.com/c/articles/61863660/disordered-eating-behaviors-depression-anxiety-stress-among-ma laysian-university-students

[8] Al-Ani, Radeef, A.S. and Ghazi, F.G. (2015) Depression, Anxiety and Stress among Undergraduate Science Students in Malaysia. $17^{\text {th }}$ Johor Mental Health Conference, Malaysia, 17-18 April 2015, Unpublished. http://irep.iium.edu.my/42809/

[9] Radeef, A.S., Faisal, G.G., Ali, S.M. and Ismail, M.K.H.M. (2014) Source of Stressors and Emotional Disturbances among Undergraduate Science Students in Malaysia. International Journal of Medical Research \& Health Sciences, 3, 401-410. http://dx.doi.org/10.5958/j.2319-5886.3.2.082

[10] Safree, M.A., Yasin, M. and Dzulkifli, M.A. (2011) Differences in Depression, Anxiety and Stress between Low- and High-Achieving Students. Journal of Sustainability Science and Management, 6, 169-178. http://jssm.umt.edu.my/files/2012/01/19.June11.pdf

[11] Zaid, Z.A., Chan, S.C. and Ho, J.J. (2007) Emotional Disorders among Medical Students in a Malaysian Private Medical School. Singapore Medical Journal, 48, 895-899.

http://www.researchgate.net/publication/5934756 Emotional disorders among medical students in a Malaysian pri vate medical school

[12] Ronk, F.R., Korman, J.R., Hooke, G.R. and Page, A.C. (2013) Assessing Clinical Significance of Treatment Outcomes Using the DASS-21. Psychological Assessment, 25, 1103-1110.

http://www.researchgate.net/publication/237015113_Assessing_Clinical_Significance_of_Treatment_Outcomes_Using the_DASS-21

http://dx.doi.org/10.1037/a0033100

[13] Gomez, F. A Guide to the Depression, Anxiety and Stress Scale. http://www.iwsml.org.au/images/mental_health/Frequently_Used/Outcome_Tools/Dass21.pdf

[14] Anonymous (2014) Overview of the DASS and Its Uses. http://www2.psy.unsw.edu.au/Groups/Dass/over.htm 
[15] Anonymous (2013) Depression Anxiety Stress Scale-21 (DASS-21).

http://www.scireproject.com/outcome-measures-new/depression-anxiety-stress-scale-21-dass-21

[16] Henry, J.D. and Crawford, J.R. (2010) The Short-Form Version of the Depression Anxiety Stress Scales (DASS-21): Construct Validity and Normative Data in a Large Non-Clinical Sample. British Journal of Clinical Psychology, 44, 227-239.

http://onlinelibrary.wiley.com/doi/10.1348/014466505X29657/abstract;jsessionid=FD33C9C042CDCB1E17BCE4861 51CFAC6.f03t02?userIsAuthenticated=false\&deniedAccessCustomisedMessage $=$ http://dx.doi.org/10.1348/014466505X29657

[17] Nieuwenhuijsen, K., de Boer, A.G.E.M., Verbeek, J.H.A.M., Blonk, R.W.B. and vanDijk, F.J.H. (2002) The Depression Anxiety Stress Scales (DASS): Detecting Anxiety Disorder and Depression in Employees Absent from Work Because of Mental Health Problems. Occupational \& Environmental Medicine, 60, i77-i82.

http://oem.bmj.com/content/60/suppl_1/i77.short http://dx.doi.org/10.1136/oem.60.suppl_1.i77

[18] Shamsuddin, K., Fadzil, F., Wan Ismail, W.S., Azhar Shah, S., Omar, K., Muhammad, N.A., et al. (2013) Correlates of Depression, Anxiety and Stress among Malaysian University Students. Asian Journal of Psychiatry, 6, 318-323. http://www.researchgate.net/publication/243966318_Correlates_of_depression_anxiety_and_stress_among_Malaysian _university_students http://dx.doi.org/10.1016/j.ajp.2013.01.014

[19] Cohen, S. and Wills, T.A. (1985) Stress, Social Support, and the Buffering Hypothesis. Psychological Bulletin, 98, 310-357. http://psycnet.apa.org/journals/bul/98/2/310/ http://dx.doi.org/10.1037/0033-2909.98.2.310

[20] Cohen, S. and Hoberman, H.M. (1983) Positive Events and Social Supports as Buffers of Life Change Stress. Journal of Applied Social Psychology, 13, 99-125. http://repository.cmu.edu/cgi/viewcontent.cgi?article=1264\&context=psychology http://dx.doi.org/10.1111/j.1559-1816.1983.tb02325.x

[21] Everson, S.A., Maty, S.C., Lynch, J.W. and Kaplan, G.A. (2002) Epidermiological Evidence for the Relation between Socioeconomic Status and Depression, Obesity, and Diabetes. Journal of Psychosomatic Research, 53, 891-895. http://deepblue.lib.umich.edu/handle/2027.42/51444 http://dx.doi.org/10.1016/S0022-3999(02)00303-3

[22] Monroe, M.L., Edward, P.T. and Neal, H.G. (1980) Childhood Depression, Family Income, and Locus of Control. Journal of Nervous \& Mental Disease, 168, 732-735. http://journals.lww.com/jonmd/Abstract/1980/12000/Childhood_Depression,_Family_Income,_and_Locus_of.4.aspx

[23] MohdSidik, S., Rampal, L. and Kaneson, N. (2003) Prevalence of Emotional Disorders among Medical Students in a Malaysian University. Asia Pacific Family Medicine, 2, 213-217. http://onlinelibrary.wiley.com/doi/10.1111/j.1444-1683.2003.00089.x/abstract http://dx.doi.org/10.1111/j.1444-1683.2003.00089.x

[24] Kean, D. and Pamela, E. (2005) The Influence of Parent Education and Family Income on Child Achievement: The Indirect Role of Parental Expectations and the Home Environment. Journal of Family Psychology, 19, 294-304. http://psycnet.apa.org/journals/fam/19/2/294/ http://dx.doi.org/10.1037/0893-3200.19.2.294

[25] Radeef, A.S., Faisal, G.G., Ali, S.M. and Ismail, M.K.H.M. (2014) Source of Stressors and Emotional Disturbances among Undergraduate Science Students in Malaysia. International Journal of Medical Research \& Health Sciences, 3 , 401-410.

http://ijmrhs.com/source-of-stressors-and-emotional-disturbances-among-undergraduate-science-students-in-malaysia/ http://dx.doi.org/10.5958/j.2319-5886.3.2.082 